\title{
The Bathroom in Housing Architecture: From a Place of Personal Hygiene to a Place of Well-Being
}

\author{
Simona Canepa \\ Department of Architecture and Design, Politecnico di Torino, Torino 10125, Italy
}

\begin{abstract}
In addition to personal hygiene, bathrooms also have an important function at the emotional level when it comes to taking time out, indulging and relaxing. Planners are increasingly required to deal with customer desires and offer personalised solutions, in addition to knowing about the technical requirements and movement areas of sanitary facilities. Besides producing well designed floor plans, experts need to take into account sustainability and accessibility, as well as materials, light, colour, fixtures and fittings which have seen a big evolution during the years.
\end{abstract}

Key words: Bathroom evolution, bathroom design.

\section{Introduction}

A few years ago the author carried out a research on two environments that over the centuries have undergone profound changes: the kitchen and the bathroom [1]. The author felt the need to resume this research to document the profound changes that these environments are facing during the new millennium. New materials and technologies have given these two rooms of the house the same importance as the living room and bedroom areas.

In recent decades, a constant evolution of the concept and the way of living the house have conditioned the design and furnishing criteria of the entire domestic environment. The bathroom has played a leading role in this changing process, both in terms of function and aesthetic.

\section{Historical Notes}

The first example of a bathroom with hygienic appliances dates back to about $2000 \mathrm{BC}$, and was found in the palace of Knossos in Crete. It was equipped with a terracotta pot covered with wood, perforated in the center and with a drainage channel which ended in a

Corresponding author: Simona Canepa, assistant professor, research fields: interiors and exhibit. black cesspit. In the palace were also found a bathtub for ablutions and foot baths and the queen's bathtub [2].

The bath, intended as a place to free one's body from the impurities, began to develop in the early years of the Roman Empire reaching its peak in subsequent periods of greatest political and cultural splendor. There are testimonies of large spaces equipped with hot and cold running water, hot and humid air in the so-called thermal baths [3].

In the Middle Ages, on the other hand, there was an abandonment of personal hygiene practices, the use of which is reduced to a few rich people, often considering such practices as sinful.

Only towards the end of the eighteenth century, thanks to the appearance of the bourgeois class, there was a rebirth for the hygiene of the body with the consequent appearance of real environments both public and inside private homes. During the Industrial Revolution, thanks to the progress of technology and new knowledge in the medical field, there was an awareness of the disastrous hygienic conditions in which the main European cities were found.

The uncontrolled expansion of the cities and the dizzying increase of the urban population imposed a revolution in the hygienic customs. The main cities of 
the European continent were equipped with sewers and drinking water fountains, and in many cities we saw the installation of wash-tubs and public toilets. At the forefront in this field is England, which in 1846 launched the Bath \& Washouses Act, a plan to provide public baths not only in London, but also in all major cities of the Kingdom. In the last years of the century, the German Public Bathing Authority was also founded in Germany [4].

The water and its benefits were thus exalted almost everywhere and the places where to perform ablutions returned to be, after many centuries, collective spaces of socialization and meeting.

Until the mid of the nineteenth century, there were no rooms in homes comparable to the current bathrooms. Only towards the end of the century were the first bathrooms built: commonly very large rooms, as for this purpose were converted rooms with a different previous use, chosen on the basis of the criterion of easier accessibility to the pipes. Given the cost of construction, each house rarely had more than one bathroom, which was therefore used by all occupants of the house.

In those same years, many ceramic sanitaryware workshops were established in England; the costs of sanitary appliances remained very high for a long time (mainly because of the high percentage of waste), although demand gradually increased significantly.

\section{Research in America between 1890s and 1940s}

In the early years of the twentieth century, new discoveries in the field of chemistry on colloidal substances allowed in America improving the production of ceramic sanitaryware, but the introduction of production technologies of vitreous china (commonly called porcelain sanitaryware) in the construction of such equipment dates back only to the twenties. In the meantime, the technique for the production of bathtubs was also refined: in fact, the production of enamelled cast iron bathtubs and later enamelled sheet metal bathtubs was introduced.

At the same time as the development of health care equipment was taking place, the entire environment for personal hygiene was also being transformed. It is to America that we owe, as was already the case for the kitchen environment, the new design directions. The need to offer maximum comfort while taking up the minimum of space, without neglecting an image of refined design, involved architects and engineers in the transport sector, both railway and naval. Valuable solutions can be found in many Pullmann wagons and in the luxury and first-class cabins of the transatlantic liners. Even in the big American cities where in the same years, in order to better exploit the land rents, the vertical growth of the buildings developed, it was necessary to renew the design of all the service rooms connected to the plumbing systems, exploiting the research and technologies conducted in the naval field.

The first applications were found in hotels. The traveller who has found refined services on board the transatlantic liners must all the more find the same services on the ground.

The new buildings therefore imposed an extreme rationalization in the design of plumbing systems, carefully studying the designs of the skyscrapers of the early twentieth century, you can see how all the bathrooms face the internal corridors and were grouped into three or four at a time so as to take advantage of the same columns of water distribution and discharge. Moreover, all the sanitary appliances were placed on the same side of the rooms so as to bring together all the necessary connections. Thus was born the classic typology of the long and narrow bathroom with all the sanitary fixtures placed on the same side, with the exception of the bathtub placed to close the room on the short side.

This typology quickly spread throughout the North American territory.

From the mid-twenties, the minimum American bathroom model was also exported to Europe; unlike what happened in America, the first installations did 
not concern the large hotels, but the new prestigious residences [5].

\section{The First Experiments in Europe between 1900s and 1940s}

One of the first significant examples dates back to the early years of the XX century, the bathroom designed by Charles Rennie Mackintosh in the Hill House in Helensburgh near Glasgow (1902-1903), where the architect designed a large space, located in the immediate vicinity of the master bedrooms. In the bathroom, tiled in white ceramic and decorated with one of his classic recurring motifs, Mackintosh placed all the sanitary fixtures by function. The washbasin, bathtub and shower are in one corner of the room, while the toilet is a little off on the other side, hidden by a white lacquered wooden cabinet for linen, perfumes and personal items. All the appliances were of current production, but with much simpler lines than the fashions of the time, strictly white and without decorations. The shower is extraordinary, with a complex interweaving of pipes to allow the emission of different jets and targeted to different parts of the body [6].

Le Corbusier's work on the 1929 Villa Savoye in Poissy deserves great attention: in it there are several bathrooms serving the master bedrooms, for guests and also for those of the servants (Fig. 1).

Particularly interesting, however, is the bathroom serving the master bedroom of the hosts. It is obviously the largest and has some refined solutions. The toilet is located in a separate room, but accessible only from the bathroom.

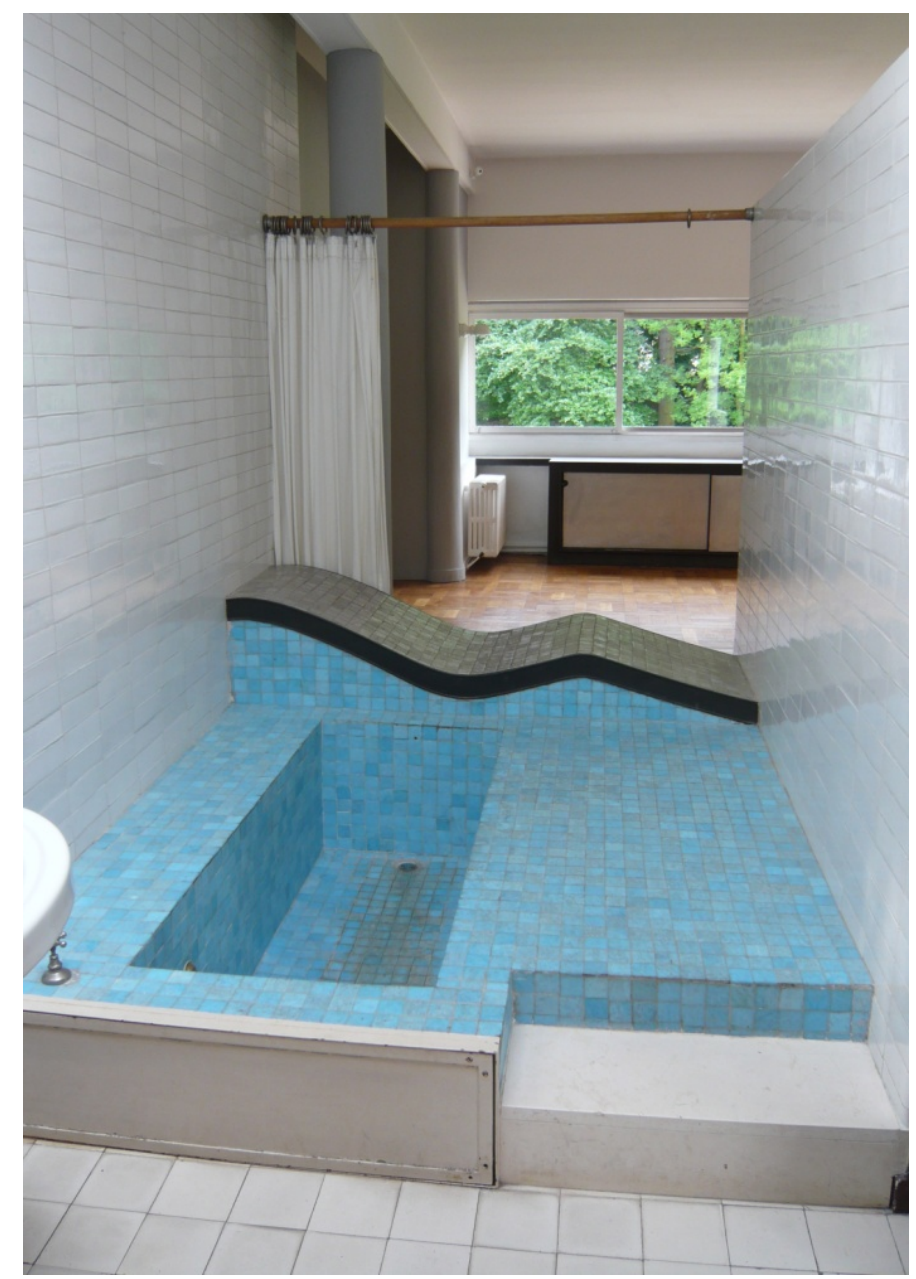

Fig. 1 Le Corbusier, the master bedroom's bathroom in Villa Savoye. 
The sanitary fixtures, washbasin, bidet and $\mathrm{WC}$, are made of white ceramic and have a very simple design compared to the models sold at the time. The bathtub, on the other hand, is entirely made of masonry and is covered with blue ceramic tiles with a swimming pool effect: to access it you need to climb a couple of steps, so as to create a formal division of the environment. To reinforce this image of diversification of the various parts of the bathroom, the short side of the room has been closed by a chaise-longue in masonry covered with black tiles that aesthetically recalls the famous leather armchair of the same architect. The entire bathroom - up to the ceiling and including the floor-is also tiled in white ceramic, in order to obtain an image of a clean and hygienic place [1].

Mies van der Rohe's solution for the model house at the 1931 Berlin Exhibition, in which he placed the service block in the middle of the sleeping area, as a separating element of the two undivided spaces for nightly rest, is also very interesting. This elegant toilet island is divided into two parts: one houses the bidet and the toilet, while the other houses the bathtub and the washbasin [7].

From the end of the 1920s onwards, many architects in Italy began to collaborate with sanitaryware companies, making a significant contribution to mass production, such as Richard-Ginori (1896), Pozzi (1906) and Ideal-Standard (1929).

\section{The Second Post-War Period in Europe and Italy: Production and Design}

The great building boom due to the need to rebuild the houses destroyed during the Second World War set new building standards and new health and hygiene regulations that forced the abandonment of the old toilet located in the common areas (balconies, corridors to access homes, etc.). The bathroom, fully equipped with all sanitarywares, must always be provided in all new buildings at least in its minimum size (normally indicated between 3 and 4 square meters). The most prestigious houses housed in most cases two or more bathrooms of different sizes and, frequently, a hierarchy in the quality of services and comfort to offer: the first bathroom was the master, large and luxurious, the second was the service, smaller and with the absence of the bathtub replaced by the shower tray, the third (if present) was of varying sizes and often served as a laundry [8].

A careful study of the most common types of housing frequently presented the bathroom as a preferably rectangular space of elongated shape (almost a corridor a little wider), with the short side defined by the length of the bath $(170-180 \mathrm{~cm}$.) and with the sanitary facilities almost always arranged on one of the two long sides in order to have the pipes concentrated on a single wall.

The walls of the bathroom were always tiled to a minimum height of about $140-150 \mathrm{~cm}$, while the floor had a variety of finishes. Usually in central-southern Europe, for the most luxurious bathrooms, stone or marble slabs were used (often at that time even the walls had the same covering material) or, even more frequently, grit (less expensive than the slabs), while in all the other bathrooms, ceramic tiles of various sizes and designs were used to cover the floors and walls. In the Anglo-Saxon countries and in Northern Europe, on the other hand, it was not difficult to find floors in wood, or in carpets or linoleum.

From the mid-fifties, almost exclusively in Italy, the bathroom was frequently enriched by the function of laundry following the introduction of the washing machine. The need to make room for a rather cumbersome object was frequently at the expense of the bathtub, which was either reduced in length (a seated bathtub) or replaced by the shower.

In this period the sanitary fixtures, the main components of the bathroom environment, underwent a profound transformation in their design. Historians agree that Giò Ponti deserves the merit of having renewed the shapes of the sanitary fixtures: the design of the P series designed in 1953 for the company Ideal Standard, revolutionized the way of conceiving the 
bathroom that became an environment to live and show. The series was an immediate commercial success, reaching in a few years to sell about 400.000 pieces a year. The washbasin was trapezoidal, a shape that favored the gesture of the arms in washing [9].

In 1954 Giuseppe Gariboldi designed the Olympic series for Richard-Ginori; Achille Castiglioni designed the Acquatonda series for Ideal Standard in 1971 and the Linda series in 1977, selected for the Compasso d'Oro award in 1979.

These were the years in which the so-called "functional bathroom" appeared, in which next to the sanitary fixtures there were modular furniture, conceptually derived from those for the kitchen. The technology put on the market three new products that brought in a short time a real revolution in the bathroom: the single lever cartridge mixer, the boxes for the drain to be embedded in the walls and the baths in methacrylate.

The single lever mixer revolutionized the aesthetics of both the controls for opening the water, always assuming new shapes and sizes, and the aesthetics of the sanitary ware on which it was mounted. Built-in cisterns made it possible to save space in the bathroom. The methacrylate bathtubs allowed the traditional heavier enamelled cast iron production to be gradually abandoned; they could also be printed in different shapes and more ergonomically correct.

It was also possible to choose between suspended or floor-standing sanitary fixtures. Suspended sanitary fixtures are the ideal choice if you prefer that nothing rests on the floor to facilitate cleaning and to have the continuity of the floor itself.

\section{The Bathroom Revolution from the 1980s to the Present Day}

The 1980s can be seen as the beginning of a new bathroom revolution. Sociologists define them as the years of hedonism: they are certainly the years in which the myth of the personal image is affirmed. This way of thinking also quickly conditions the way of living the house. You need to show that you can also live in fashion in your own home and show off all the latest status symbols. The latest fashion bathroom is certainly one of these status symbols. All manufacturers of sanitary ware take advantage of this trend and encourage it by producing objects that have to support the narcissism of their customers.

The 80s saw the centrality and care of the body, promoting the development of new concepts of design and business (such as gyms and wellness centers). In this context, the bathroom sets aside the dimension of service, ennobling itself to an environment of relaxation, well-being and body care. Each design element of the bathroom takes on significant importance for achieving a precise atmosphere and everything contributes to satisfying the specific living needs and lifestyles of those who live in it.

The sanitary fixtures are available in different materials, such as vitrified porcelain (the classic vitreus-china), fine porcelain stoneware, methacrylate or other acrylic and plastic resins, steel (galvanized, enamelled and stainless steel), glass, stone, wood (naval plywood) and also different combinations of idealit, cristalplant, marble resin, corian, birch wood for the bathtubs, vegetable resins for the sinks [8].

Towards the end of the twentieth century we also witness the phenomenon of the dismemberment of the bathroom, moving some of the activities typical of washing in other environments, for example in the bedroom or living room (Fig. 2).

Here then are small sanitary cells (2-3 square meters) equipped exclusively with a toilet, bidet and a small washbasin; washbasins placed in the hallways and closets or dressing rooms of the bedrooms, bathtubs and multi-purpose shower cubicles installed in the bedrooms or in special rooms also equipped with gymnastic equipment, with the specific purpose of characterizing the environment (Fig. 3).

Equipped with shelves and open compartments in which to place vases, books and ornaments, and storage compartments and drawers to store the necessities for 


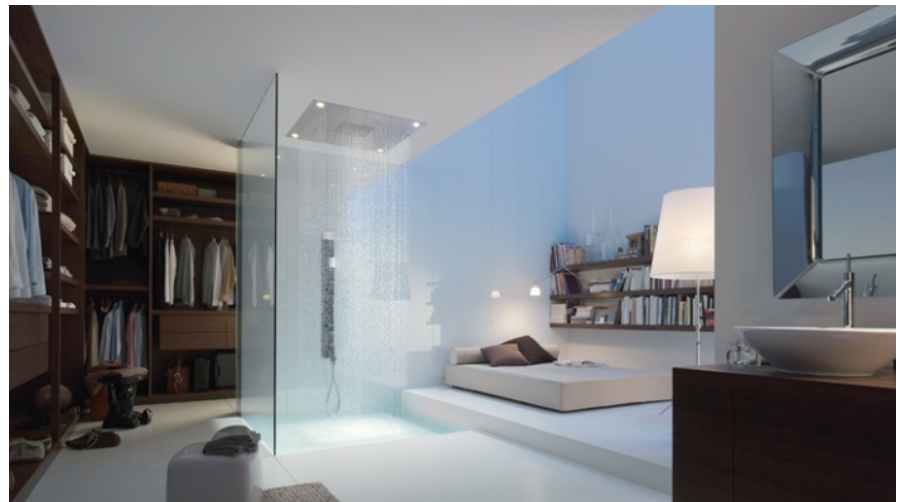

Fig. 2 Shower environment in the bedroom (Axor shower by Philippe Starck).

Source: www.pro.hansgrohe-int.com.

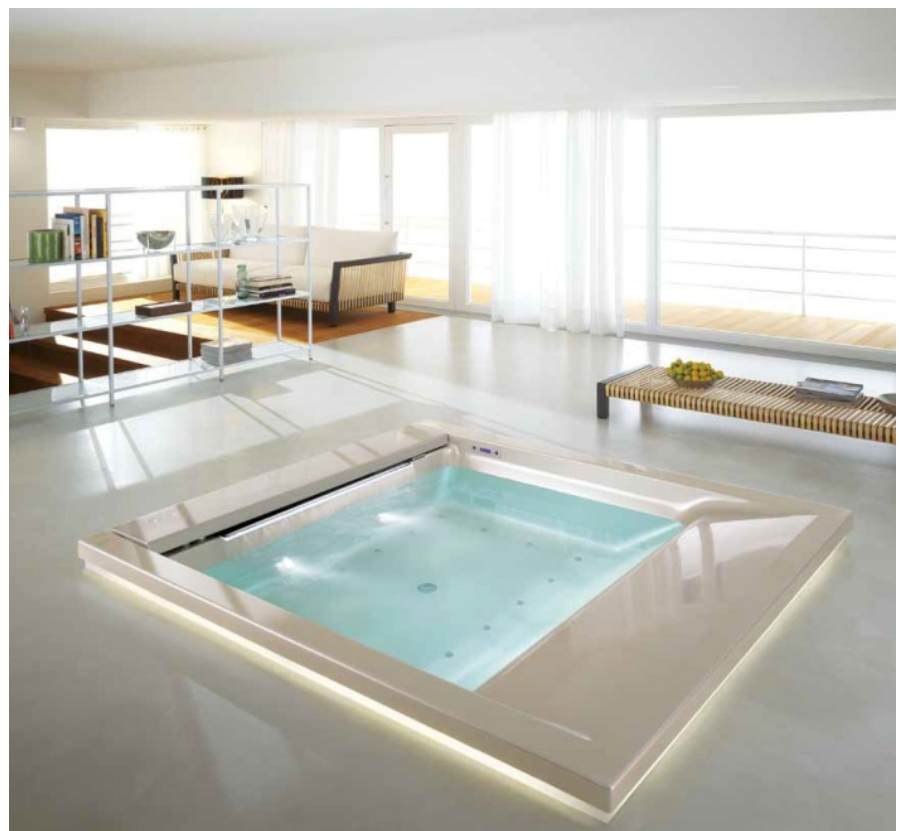

Fig. 3 Bathtub environment in the living room (seaside bathtub by Giovanna Talocci).

Source: www.idralia.it.

the toilet, the contemporary bathroom furniture is elegant and functional at the same time, thanks to the use of quality materials combined with a design with essential lines: the washbasins are integrated into the top, while the countertop models are transformed into refined objects of design like ornaments (Figs. 4 and 5).

At the same time, the bathroom is accessed by the sauna, as complement equipment, accompanied by a dressing room and a room to rest and relax (Fig. 6).

The bathroom is therefore a place of well-being, relaxation, self-care, a place of decompression and relaxation, an environment in which there are aspects and discoveries related to aromatherapy, colour therapy and water massage (Fig. 7).

In recent years there has been a trend to recreate a small wellness center in your home with all the comforts, furnishing the bathroom as if it were a mini spa. The stress of the hectic pace of everyday life is countered by the need to treat oneself to relaxing breaks and take care of oneself alone or in company. Thanks to the innovative designs, the bathtubs also become furnishing accessories, absolute protagonists in the environment in which they are installed: beautiful to see as well as to use (Fig. 8). They can be 


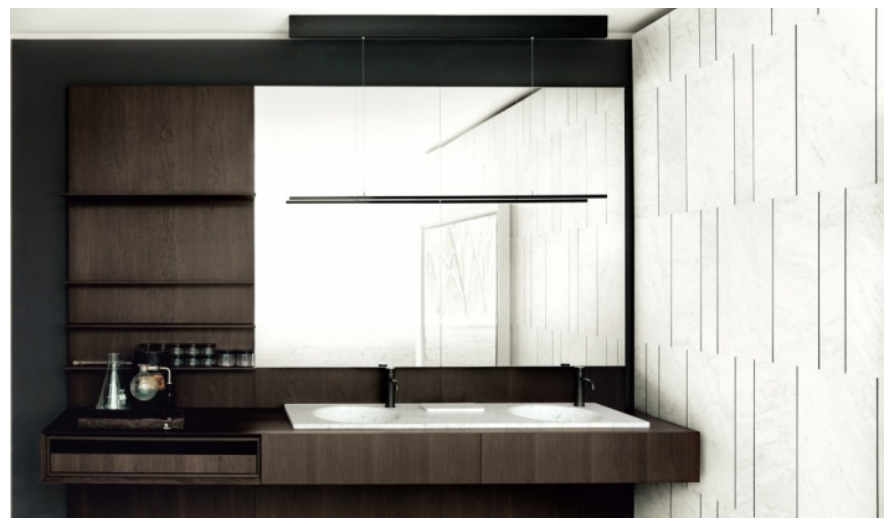

Fig. 4 Washbasin integrated into the top Boffi collection.

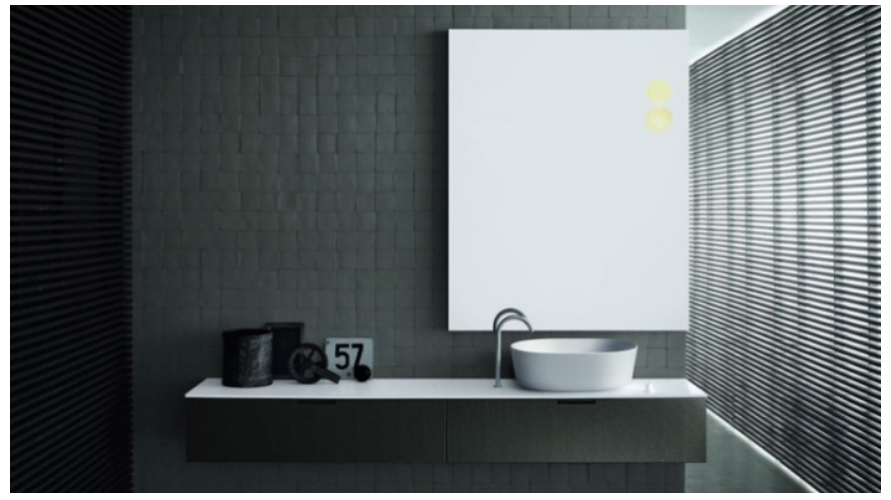

Fig. 5 Countertop washbasin Boffi collection.

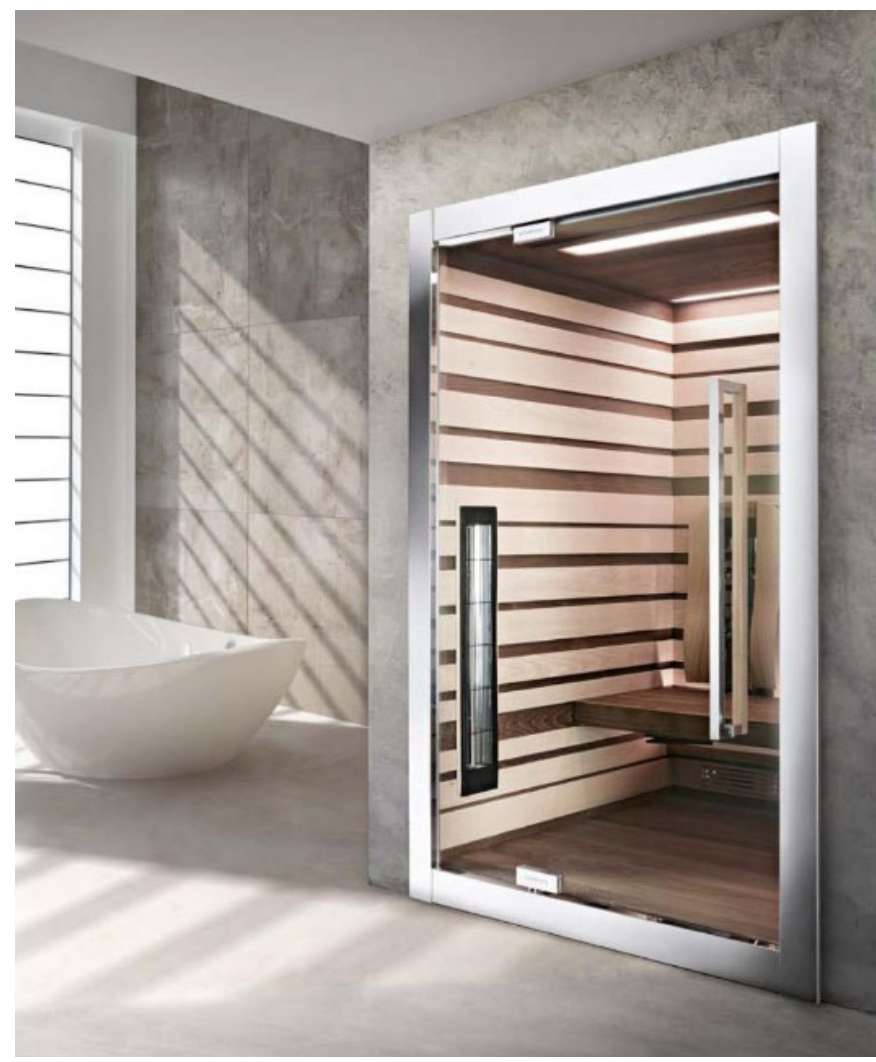

Fig. 6 Example of sauna environment in a bathroom. 


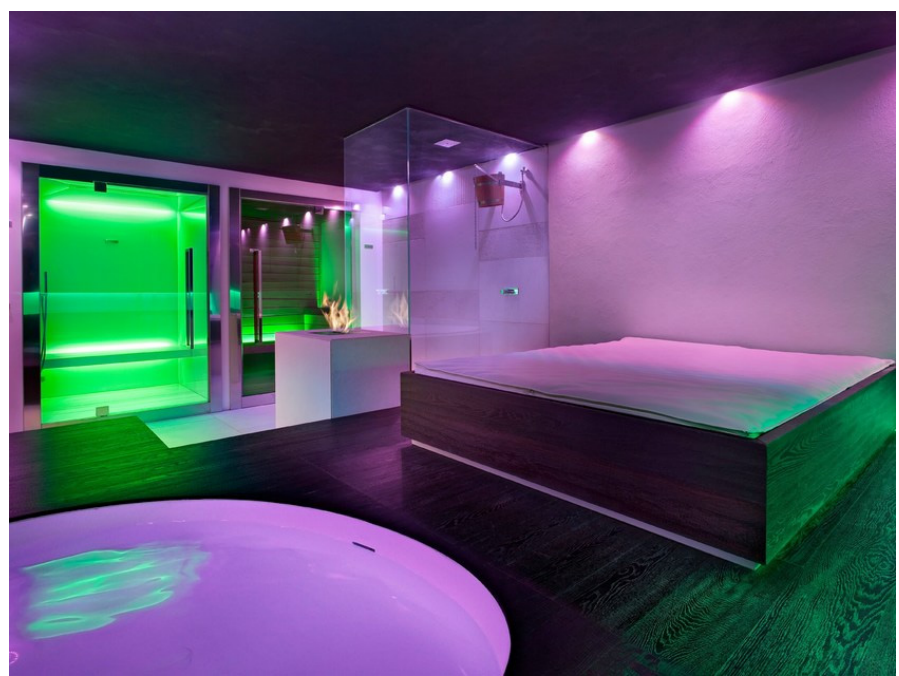

Fig. 7 Effects of colour therapy in a bathroom.

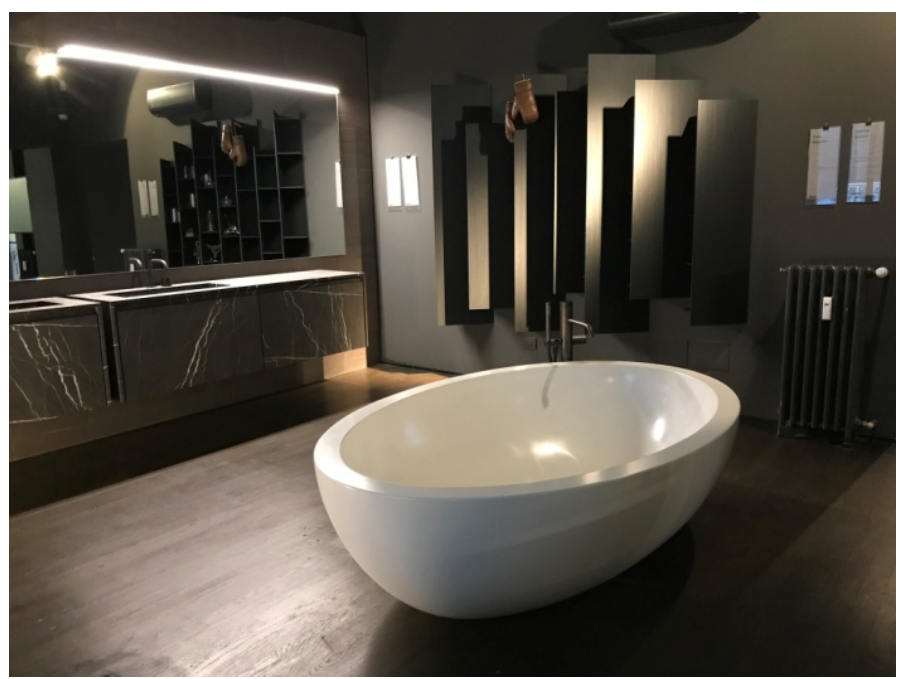

Fig. 8 Freestanding bathtub Boffi collection.

inserted in the space at will, because the bathroom transforms from a rigid place to a soft, harmonious and welcoming space.

Even the shower, normally placed in a corner of the room, is transformed: the plate at the base becomes increasingly thinner, becomes flush with the floor and the glass can go up to the ceiling (Fig. 9).

The bathroom is enlarged and transformed into a wellness bathroom: a space dedicated to the gym, with furnishing solutions designed to be used as gymnastic equipment. Gym space is Scavolini Bathroom's project presented at the Salone del Mobile 2018 in Milan designed by Mattia Pareschi, which proposes a fusion of bathroom and gym to offer the public the opportunity to furnish the environment in an organized and functional way without forgetting wellness [10]. By redesigning the typical elements of bathroom furniture, combining them with a wall structure dedicated to physical activity, Scavolini bathroom brings the fitness area into everyday life, proposing a new concept of wellness (Fig. 10).

This proposal introduces fitness corners that require the use of useful equipment to keep fit and defines a new way of conceiving the bathroom, more and more expression of the concept of wellness and lifestyle. The heart of the project lies in the reinterpretation of the Swedish framework, used as a base to apply additional sports equipment and to fix bathroom accessories—such 
Fig. 9 Shower Jacuzzi collection.
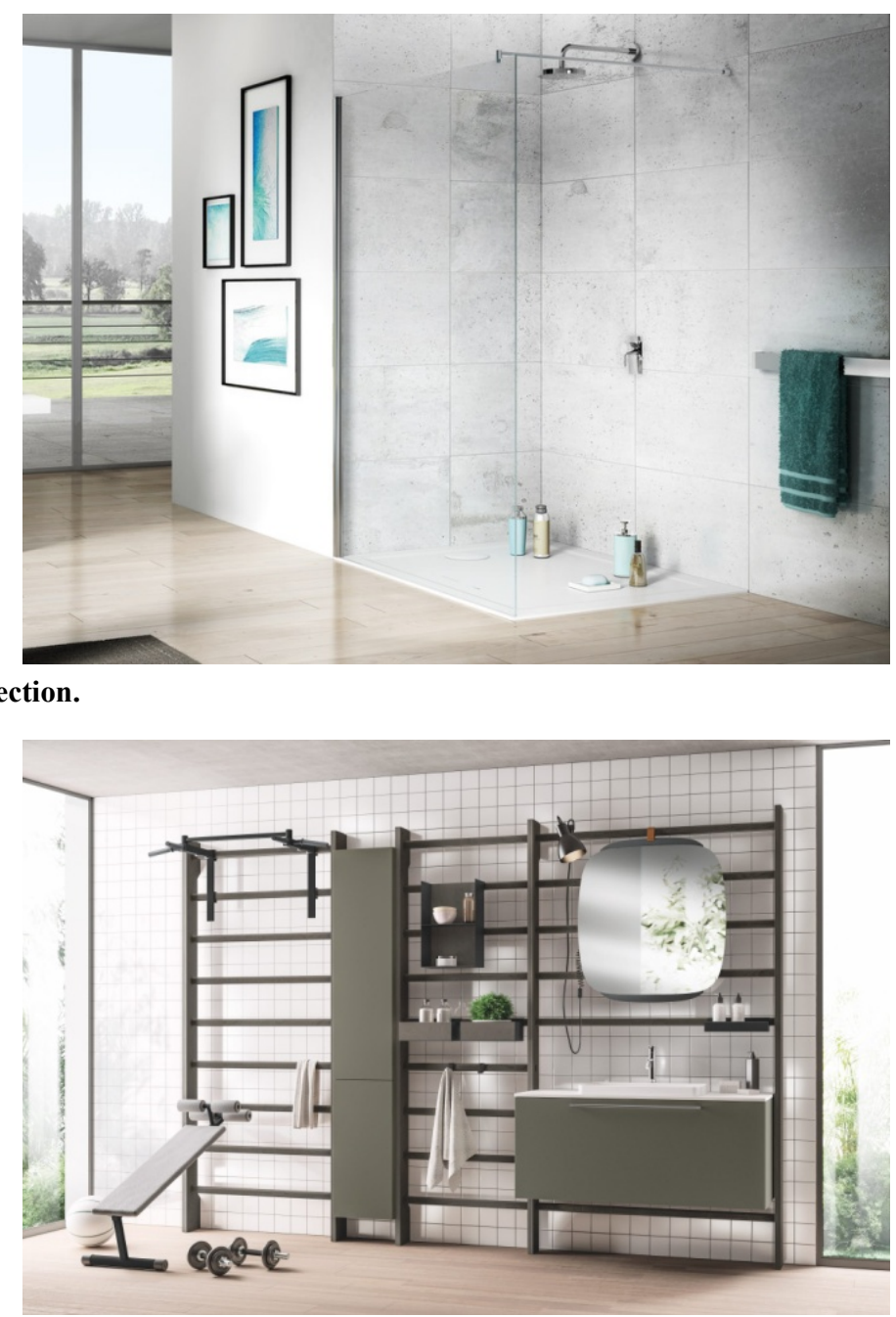

Fig. 10 Gym space by Scavolini.

as lights, soap dishes, shelves, storage elements and mirrors.

Fifty years after inventing the bubble bathtub, Jacuzzi proposes the vortex of water to give new sensations to the relaxing bath: a vortex of water that embraces the body with a circular and continuous movement of the water that is also maintained at the desired temperature for the duration of the bath (Fig. 11). This new jet is complemented by other functions such as chromotherapy with soft LED lights that fade into each other in a slow and gradual way. But even more innovative is the integrated salt infuser [11].

Taps and mixers, washbasin, shower and bathtub are becoming more and more protagonists of the bathroom scene and an integral part of a global project in which the finish is studied and sometimes customized to adapt to the style and materials of the environment.

In the showers, waterfalls directly from the ceiling thanks to shower systems incorporated in the horizontal structure of the roof.

And more showers with different types of jets that generate more voluminous and pleasant drops with a massaging effect thanks to the rotation of the spiral jets.

The mirror plays a leading role, thanks to the latest generation models: a complement that, thanks to the elegance and sophistication of the design, has lost its purely functional connotation, integrating perfectly into the furniture.

The LED-backlit mirrors are perfect for the bathroom in the living room style, while the smart models, 


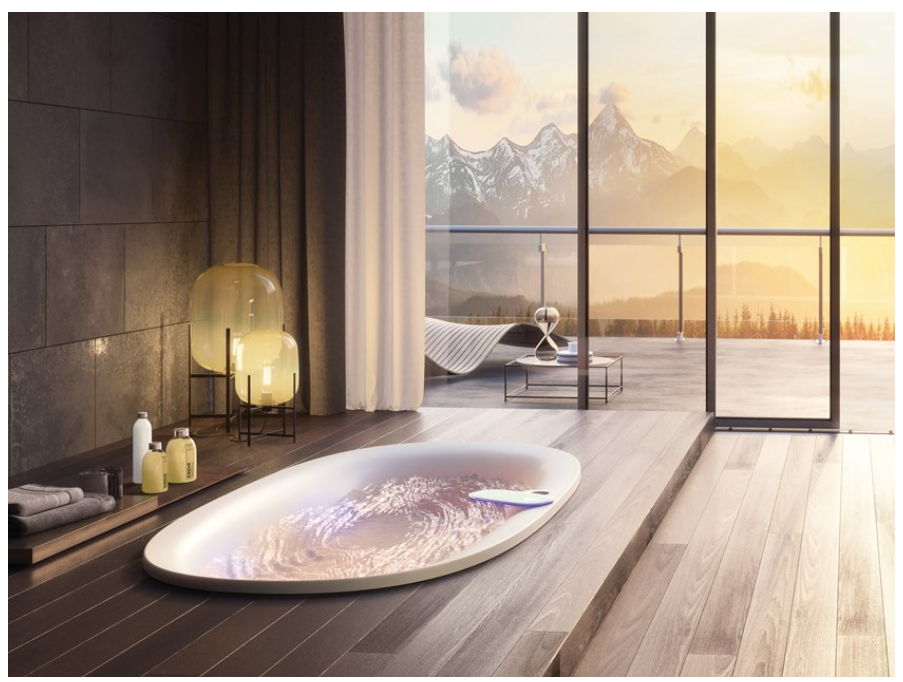

Fig. 11 The new generation of hydromassage bathtubs by Jacuzzi.

with connection to mobile devices, allow you to play music or watch a movie, just like in the living room.

Do not forget an element that is almost always present in the bathrooms and that in recent years has also undergone a radical transformation: the radiator. From being a bulky object, but indispensable for its dual function as a heating element and balancer of the amount of humidity in the room, it is transformed into an object of refined and original design, with the added function of a towel rail and heater. The new generation of radiators combine functionality with aesthetics, and are considered as real pieces of furniture (Figs. 12 and 13).

At the same time, new generations of luminaires complete the bathroom technology range. A good compromise between functionality and comfort can now be achieved by integrating so-called service lamps with LED strips along the contours of walls or other elements such as niches, shelves or the profiles of the bathtub and shower cubicle.

\section{Architects and Designers at the Service of the Bathroom Environment}

We have already mentioned the collaboration of architects in the 1950s with ceramic and sanitaryware companies.

Many other architects and designers have linked their names to leading companies in the production of sanitary ware and fittings over the last few decades.

The collaboration between Arne Jacobsen and Vola A/S started in 1968 when its owner, Verner Overgaard, contacted Arne Jacobsen and introduced his proposal for a new type of wall-mounted mixer. He imagined a design where all the mechanical parts of the mixer are hidden leaving only the spout and handle seen by the user. At this time this was a completely new concept, but Jacobsen realized that this idea combined with his functionalistic approach to design could be developed. The first VOLA mixers were designed for the National Bank of Denmark [12].

Franco Bertoli designed in 1984 the Small line of Ideal Standard: every bathroom, small or large, must allow exploiting the spaces in a beautiful and functional way. With the right design, even the smallest bathrooms can become comfortable: Small with the reduced size of the sanitary fixtures $(37 \times 49 \mathrm{~cm})$ that can be transformed into a bizarre proposal for those with space problems: Small + model, a sort of suspended "bench" that contains toilets and bidets integrated in a harmonious form of design (Fig. 14).

At the same time Renzo Piano designed the collection that bears his name for Ceramica Dolomite. Functionality and practicality are enhanced in his design of sanitary fixtures and taps: eccentric shapes 
Fig. 12 The new frontier of radiators: radiator over the washbasin in continuity with the mirror.

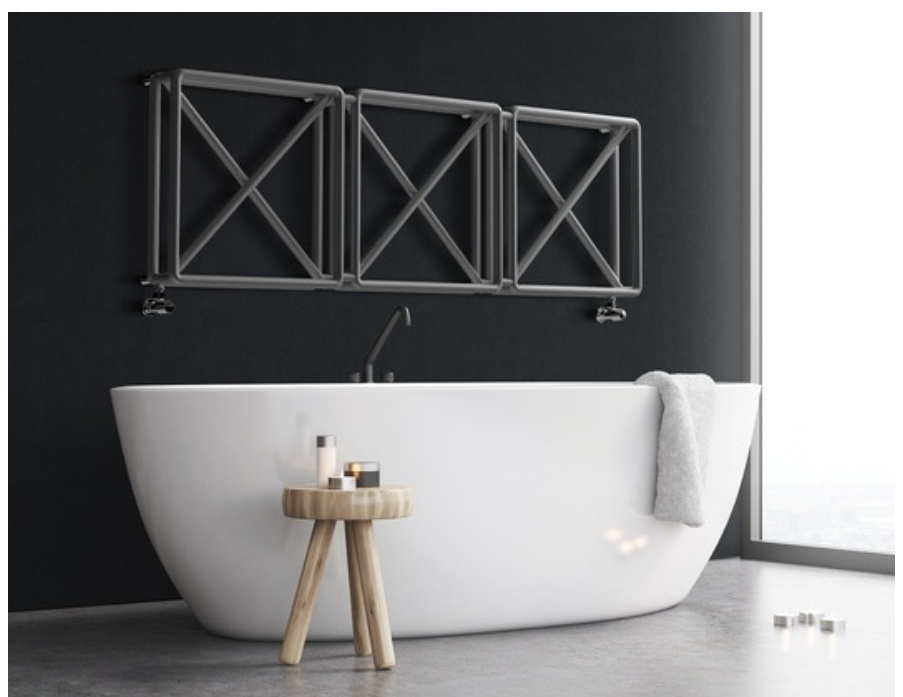

Fig. 13 The new frontier of radiators: wall-mounted radiator in the length of the bathtub.

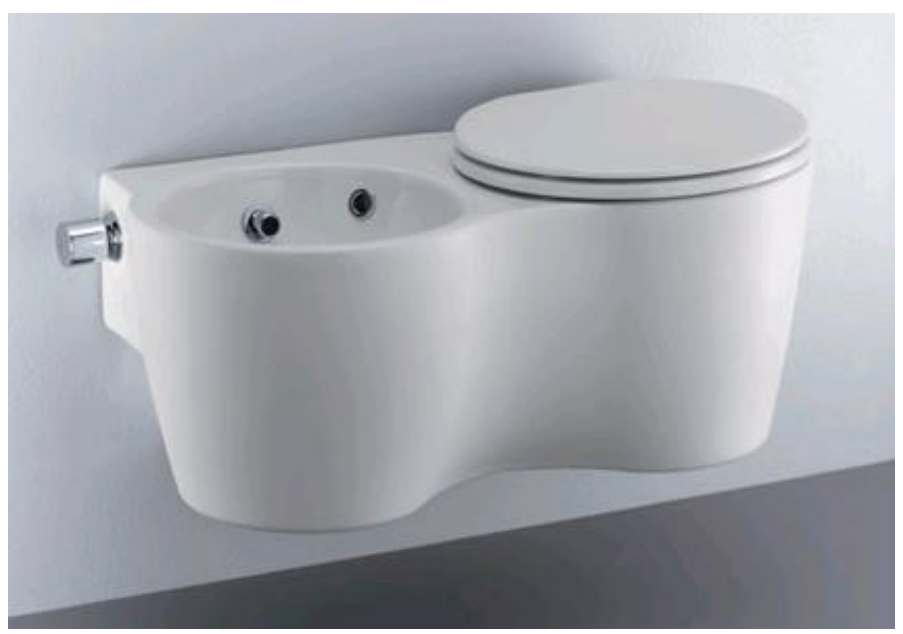

Fig. 14 Franco Bertoli, Small + model for Ideal Standard. 
have been banned to privilege the originality of traditional materials.

In 1994 Philip Starck and the Duravit Company began to collaborate with the introduction of the Starck 1 collection on the market: the vase, bathtub and washbasin are a clear reference to the reinterpretation of the bucket, tub and basin (Fig. 15).

The furniture designed for the Cape Cod collection is characterized by the use of solid wood both for the structure and for the horizontal tops and is configured as work tables never imagined before for a bathroom: they are designed with different variations both for the finish of the wood and for the shape of the washbasin above the top (Fig. 16).

Philippe Starck also designed for Duravit the electronic seats SensoWash ${ }^{\circledR}$ Starck f Plus and SensoWash ${ }^{\circledR}$ Starck $f$ Lite, to be used with the remote control and freely configurable via the app, with proximity sensor for the automatic opening of the cover when the user is seated and many options for adjusting the seat heating, the intensity of the jet of the hand shower and the hot air dryer. All harmonized by a minimalist design, which is well suited to the European bathroom [13].

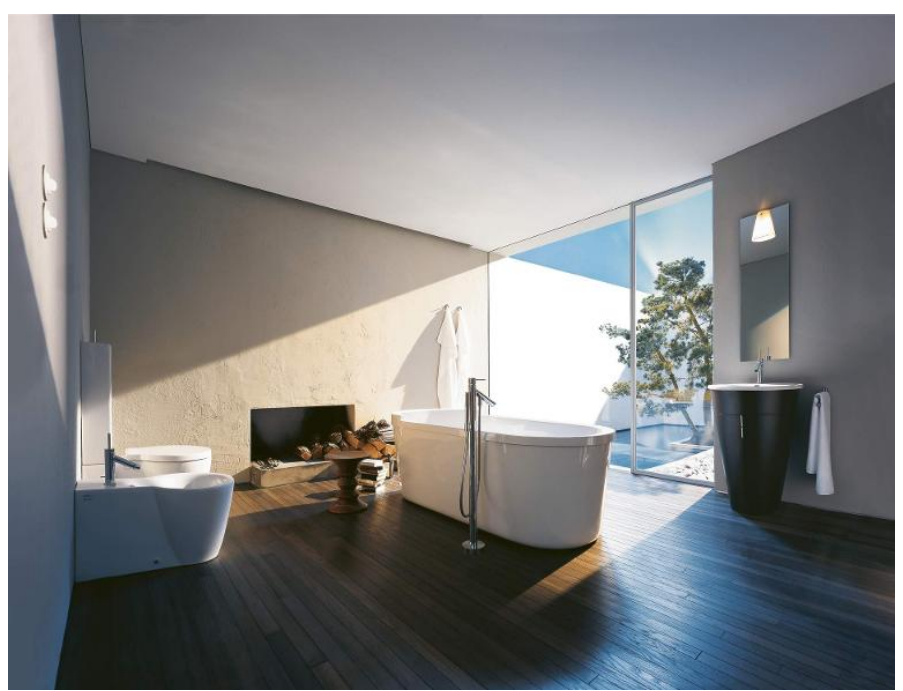

Fig. 15 Philip Stark, collection Stark 1 for Duravit.

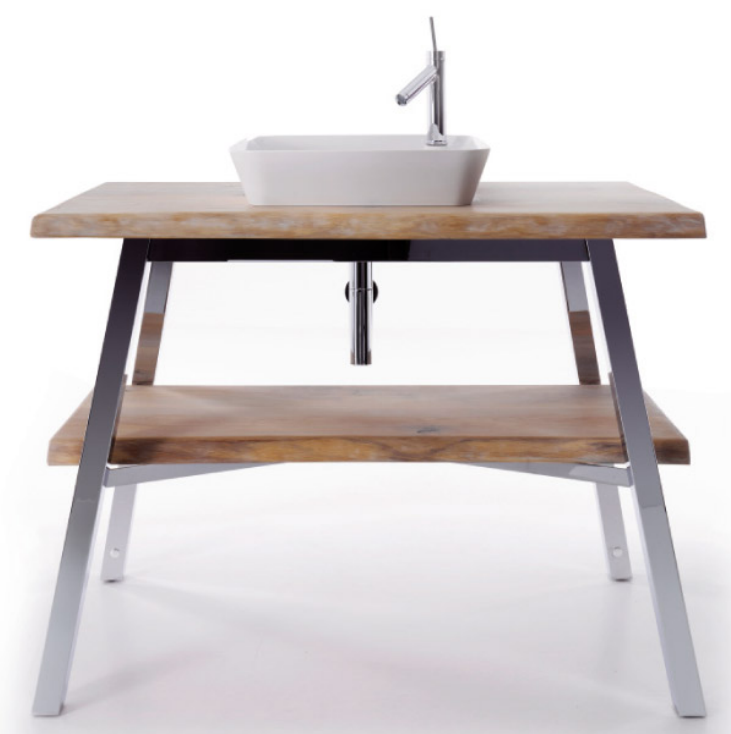

Fig. 16 Philip Stark, collection Cape Cod for Duravit. 
Fig. 17 Antonio Citterio, furniture for Pozzi Ginori.
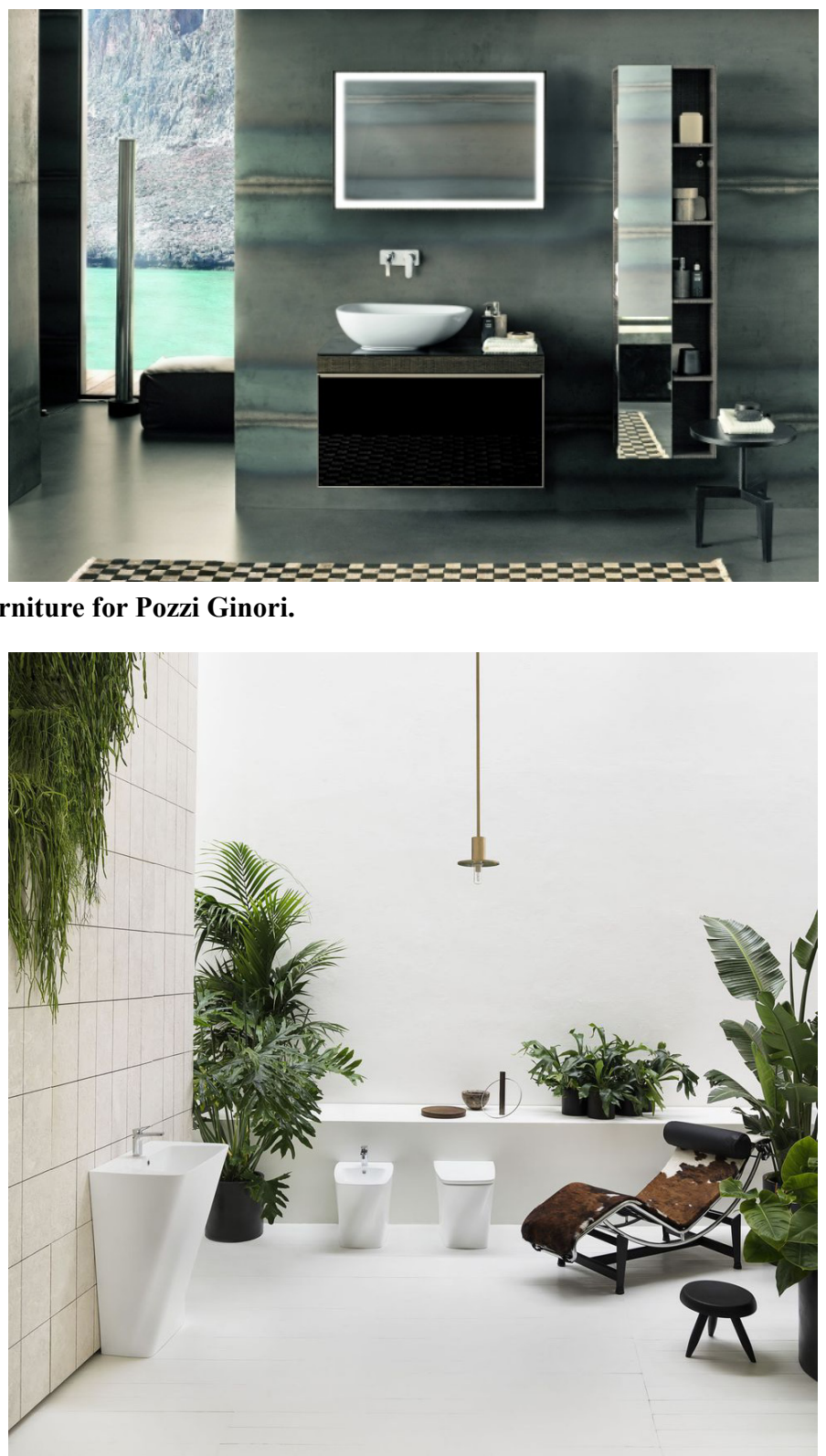

Fig. 18 Daniel Libeskind, Hera collection for Azzurra Ceramica.

Antonio Citterio for Pozzi Ginori designed over the years the collections Q3, Citterio, Novecento, easy.02, 500, egg, not only sanitaryware but also a complete system of capacious and functional containers to serve the bathroom in both horizontal and vertical versions (Fig. 17) [12].

David Chipperfield has linked his name to the Roca Company with the Element collection characterized by pure geometric lines that allow it to adapt to different environments and styles [14].

Norman Foster has created for Duravit a bathroom suite that pushes the boundaries, which defines the bathroom anew: two adjacent circles define the geometry of the whole range, plus the archetype of two cupped hands scooping fresh water [15].

Daniel Libeskind transfers the dynamic and fluid lines of his deconstructivist architecture to the bathroom, designing the Hera collection for Azzurra Ceramica (Fig. 18).

The sanitary fixtures are characterized by a twisting movement, which makes the geometry of the volumes almost unstable [16]. 
With large rings and circular arches, Foster faucets designed for Stella are ergonomic and have an essence of raw industrialism (Fig. 19). The large steering wheels like rings are iconic and easy to adjust. Like the old wheels used on industrial plumbing, the Fosters faucets bring this imagery into a sleek modern style. The high spout faucet has a slim curved pipe, which offers simplicity, while the tub mixers large form offer
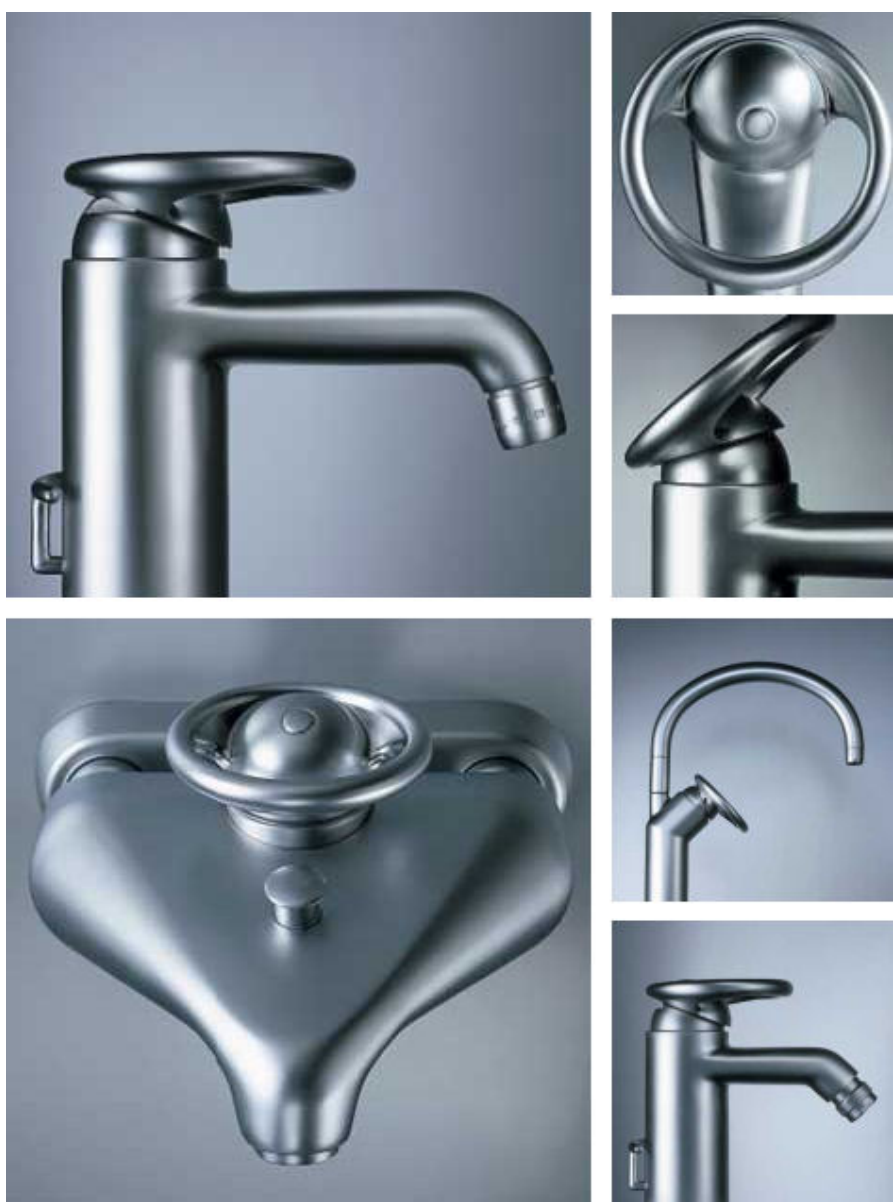

Fig. 19 Norman Foster, faucets for Stella Company.

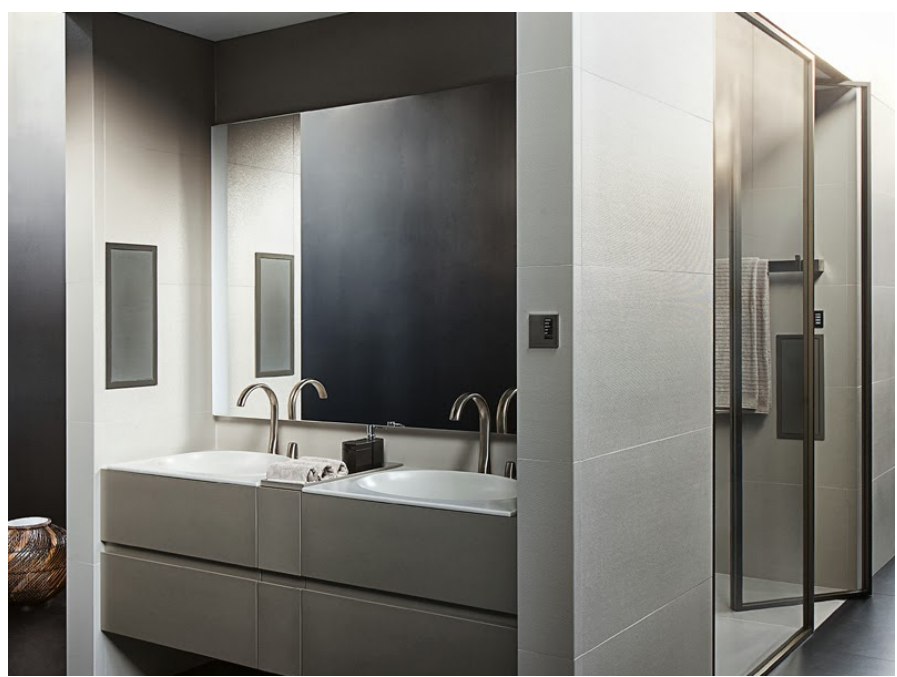

Fig. 20 Armani's proposal for Roca bathroom concept. 


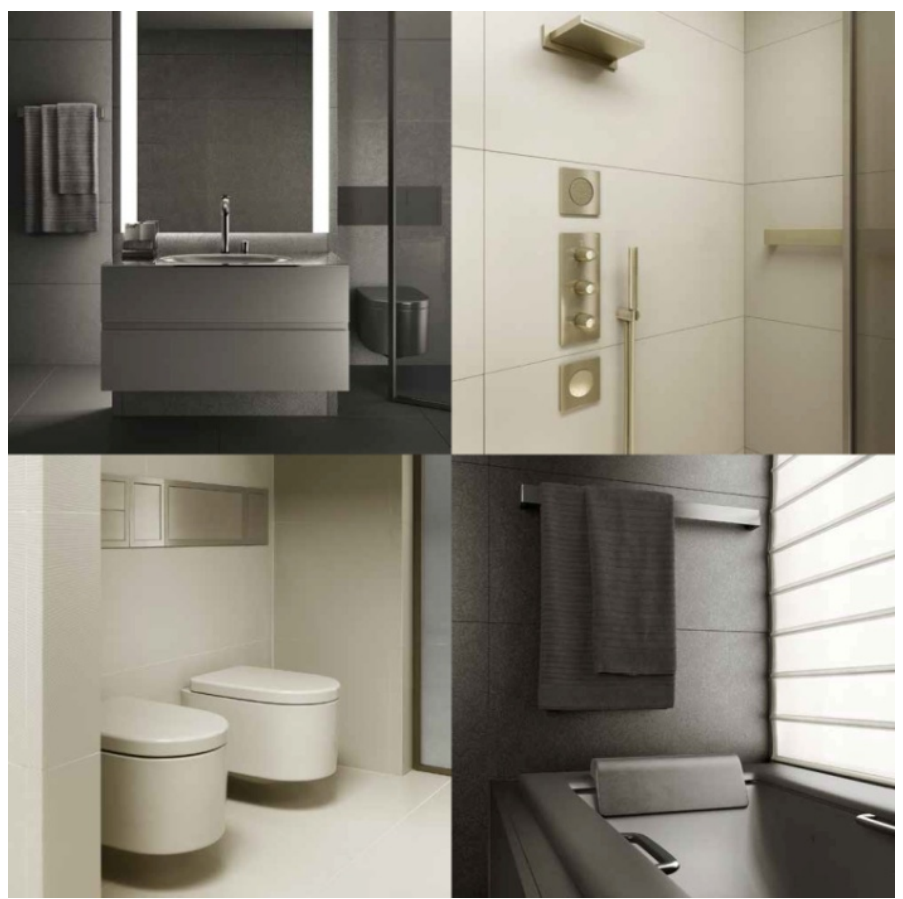

Fig. 21 Armani's Baia and Island collections for Roca.

the intriguing function-defined shapes so often found in industrial works and factories. The range includes mixers for basin, tub, bidet, high spout, and shower. The Foster faucets have specifically avoided sharp protrusions, for a safety conscious design. Applied over a nickel coat, the high quality finish is available in matte or polished chrome [17].

Since 2010 Giorgio Armani, world famous fashion designer, and the Spanish company Roca have created a partnership that combines elegant and sophisticated luxury with the most advanced technological solutions, transforming the bathroom into a place suitable to stimulate the five senses and give pleasure [18]. The Armani/Roca bathroom includes not only sanitary fixtures, but also wall and floor cladding, ceiling lighting, taps, fittings and accessories designed to give the project a unified look. Armani designed the bathroom space as an island which integrates all the essential elements of the bathroom in a solid divided into four functional areas: wellness area with bathtub, beauty area, wellness area with shower and toilet area (Figs. 20 and 21).

\section{Conclusions}

Today the bathroom is perhaps the environment that is undergoing the most radical transformations and remains one of the most complex to design because of the many possibilities of use, in which the functional aspects are accompanied by those playful, resulting from the introduction of the concept of comfort. The bathroom becomes a space to live in, a space that favours the encounter between body and mind.

In line with the new trends of the sector, which see all the rooms of the house furnished in a homogeneous and harmonious way, the collections of bathroom furniture are increasingly inspired by the furniture of the living space: modular elements conquer the bathroom, as if it were an extension of the furniture of the living room.

As Giulio Cappellini, art director of Flaminia since 2004, says, the bathroom has evolved from a service room to a wellness room, a room where time can be spent. In describing the bathroom of his house he says that ".. there are books, paintings, candles, carpets, because in this room you can tell yourself..." [19]. 


\section{References}

[1] Vaudetti, M., and Canepa, S. 2010. Interior Architecture and House Project. Torino: Utet Scienze e Tecniche. (in Italian)

[2] Bersani, E., Boeri, G. P., Battiston, G., and Persi, E. 2010. The Bathroom. Roma: EPC Libri. (in Italian)

[3] Von Hesberg, H., and Zanker, P., eds. 2009. Architettura romana, i grandi monumenti di Roma. Milano: Garzanti. (in Italian)

[4] Lupton, E., and Abbot Miller, J. 1992. The Bathroom, the Kitchen and the Aesthetics of Waste. New York: Princeton Architectural Press.

[5] Vivanti, L. 1999. "Bathroom Evolution." In Interior Refurbishment and Design, edited by Vaudetti, M., and Bricarello, G., Torino: Utet. (in Italian)

[6] Mc Kean, C. 2000. Charles Rennie Mackintosh. Edinburg:
London Books.

[7] Cohen. J. L. 2007. Mies van der Rohe. Basel: Birkenhauser.

[8] Tardelli Palmizi, A. 1994. The Sanitary Appliance and the Design. Milano: PEG. (in Italian)

[9] Ponti, L., 1990. Gio Ponti the Work. Milano: Leonardo Edizioni. (in Italian)

[10] www.scavolini.com.

[11] www.jacuzzi.com.

[12] Thau, C., Vindum, K., 2001. Arne Jacobsen. Copenaghen: Danish Architectural Press.

[13] www.duravit.com.

[14] www.roca.com.

[15] www.duravit.com.

[16] www.azzurraceramica.com.

[17] www.rubinetteriestella.it.

[18] www.armaniroca.com.

[19] www.ceramicaflaminia.it. 